\title{
卤代烃教学中课程思政的探索与实践
}

李楚玉, 王泽华, 方志强, 周子昕, 林青青, 王云侠, 赵军龙 ${ }^{*}$, 王兰英*

西北大学化学与材料科学学院, 化学国家级实验教学示范中心, 西安 710127

摘要: 在有机化学教学中推进 “课程思政” 建设, 对于落实 “立德树人” 根本任务具有重要意义。本文以卤代烃章 节的讲授为例, 引入芥子气化学武器、氟利昂制冷剂、氟烷麻醉剂、有机氯杀虫剂和格利雅试剂等事例, 探讨在教 学中将专业知识、专业科普和专业思政进行深度融合, 使学生全面客观地认识卤代烃, 明白科学道路永无止境, 懂 得利用专业知识造福人类。

关键词: 课程思政; 有机化学; 卤代烃

中图分类号: G64; O62

\section{Exploration and Practice of Course Ideology and Politics in Halocarbon Teaching}

\author{
Chuyu Li, Zehua Wang, Zhiqiang Fang, Zixin Zhou, Qingqing Lin, Yunxia Wang, Junlong Zhao *, \\ Lanying Wang * \\ National Demonstration Center for Experimental Chemistry Education, College of Chemistry \& Materials Science, \\ Northwest University, Xi'an 710127, China.
}

\begin{abstract}
Promote the construction of "course ideology and politics" in organic chemistry teaching is of great significance for the implementation of the fundamental task of "establishing moral integrity in cultivation". Taking the teaching of halocarbons as an example, this paper introduces some examples including chemical weapons: mustard gas, refrigerants Freon, anesthetics halothane, organochlorine insecticides and the Grignard reagent to discusses the in-depth integration of professional knowledge, professional popularization of science ideological and political contents in each link of teaching, in order that students can have a comprehensive and objective understanding of halogenated hydrocarbons, and understand that the road of science is endless. Finally they will get to know how to use professional knowledge rationally and scientifically to benefit mankind.
\end{abstract}

Key Words: Course ideology and politics; Organic chemistry; Halocarbon

2019年3月18日，习近平总书记在人民大会堂主持召开学校思想政治理论课教师座谈会时强调， 要把思想政治工作贯穿教育教学全过程, 在思政教育中注重发挥教师的主导性和学生的主体性 ${ }^{[1]}$ 。 在有机化学教学中推进 “课程思政” 建设, 可以让学生在学习中潜移默化地接受思想教育, 培养创 新精神, 树立正确的人生观、价值观和世界观, 实现树立远大理想与脚踏实地奋斗相协调, 从而达 到高等教育 “既教书又育人” 的目的。我们课程组在进行集体备课时, 深挖基础有机化学课程中的 思政元素, 将这些元素有机地融入所讲授的知识点之中, 促进学生思想认识不断深化、价值观念逐

收稿: 2020-10-30; 录用: 2020-12-21; 网络发表: 2020-12-28

“通讯作者, Emails: zhaojunlong327@163.com (赵军龙); wanglany@nwu.edu.cn (王兰英)

基金资助: 国家一流专业建设项目; 国家级大学生创新创业训练计划项目(S202010697115S); 西北大学大学生创新创业训练计划项目 
步提升 ${ }^{[2]}$ 。

卤代烃在有机合成中起着承上启下的纽带作用, 是原料和目标化合物之间的重要桥梁, 理解和 掌握卤代烃的概念、用途、主要化学性质等对于其在有机合成中的应用至关重要。卤代烃是指烃分 子中的氢被卤素原子取代得到的化合物, 自然界存在的卤代烃很少, 大部分是人工合成的, 它可以 作为制冷剂、灭火剂、气雾剂、干洗剂、溶剂等等, 给人们生产生活带来了诸多方便, 与此同时, 也会对生态环境和人类健康造成很多负面影响。我们课程组将专业知识、专业科普和专业思政相融 合, 注重课程思政教学中学生的主体性作用, 本文以卤代烃一章的教学为例, 进行 “课程思政” 的 探索与实践。

\section{1 守护珍贵和平, 远离不义战争}

讲授 “卤代烃亲核取代反应的机理”一节中的 “邻基参与机理” 时, 引入曾作为化学武器的芥 子气的邻基参与反应, 供学生学习和讨论。

芥子气(图1), 即二(2-氯乙基)硫醚, 是一种无色油状可挥发液体, 因具有类似芥末的味道而得 名。芥子气是迄今生产、储存乃至使用量最多的一种化学生物武器, 其杀伤人数占已知化学战伤亡 的八成以上，被称为 “毒剂之王”。芥子气曾被广泛用于第一次世界大战，第二次世界大战期间， 侵华日军也使用过芥子气, 造成中国军民死亡近万人。为了使化学领域的成就完全用于造福人类, 彻底消除化学武器的危害, 1992年联合国通过《禁止化学武器公约》, 我国是该公约的原始缔约国。

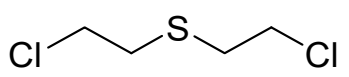

\section{图1 芥子气结构式}

芥子气通过分子内硫上的孤对电子进攻氯的 $\alpha$-碳发生 1,2 -位点的邻基参与亲核取代反应, 形成三 元环的硫鎓正离子, 生物体中氨基酸的 $\alpha$-氨基作为亲核试剂进攻硫鎓正离子的 $\alpha$-碳发生亲核取代反 应, 从而破坏蛋白质的正常功能(图2) ${ }^{[3]}$ 。

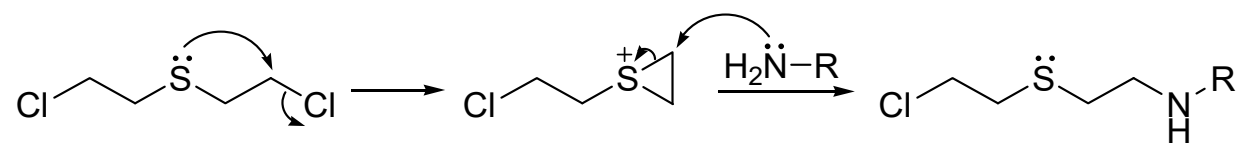

图2 芥子气的邻基参与亲核取代反应

学生感言: 在第一次世界大战中, 毒气战臭名昭著, 无论是战胜国还是战败国, 都深受其害。 自此之后, 人们逐渐认识到化学武器对人类和环境的沉重伤害, 禁止化学武器逐渐成为世界共识。 西北大学化学与材料科学学院积极宣传 “禁化武” , 连续几年被评为优秀 “禁化武” 履约工作先进 集体, 作为其中一员, 我们更应端正科学态度, 树立正确的学科价值观, 共同守护持久和平的世界。

\section{2 探索新型成果, 坚持绿色发展}

讲授 “卤代烃的命名”一节中的 “习惯命名” 时, 引入制冷剂氟利昂的发展历程, 供学生学习 和讨论。

20 世纪二、三十年代, 第一代氟利昂(CFCs) 问世, 被用于替代早期冰箱制冷剂, 以避免氨、二 氧化硫和丙烷等物质泄漏造成的事故, 给人们带来了极大的便利。一段时间后, 人们发现氟利昂会 在紫外线作用下, 分离出氯自由基, 每个氯自由基会破坏多达十万个臭氧分子, 严重破坏臭氧层 (图3)。臭氧层被损耗之后, 吸收紫外线的能力大大减弱, 给生态环境带来极大危害 ${ }^{[4]}$ 。 


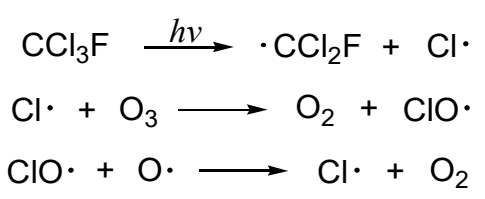

图3 氟利昂对臭氧的破坏作用

为了解决这一问题, 经过几十年的探索, 科学家陆续发明了第二、三、四代制冷剂。氢氯氟烃 类物质(HCFCs)作为第二代制冷剂, 如图4中R123, 由于加入了氢原子, 减少氯自由基的产生, 在一 定程度上减少了对臭氧层的破坏; 第三代氢氟烃类物质(HFCs), 如图4中R125, 分子内不含氯原子, 消除了对臭氧层的破坏，但会造成温室效应；第四代碳氢氟类物质(HFOs), 如图4中R1234ze, 是目 前为止最为环保的制冷剂 ${ }^{[5]}$ 。<smiles>FC(F)(F)C(Cl)Cl</smiles>

$\mathrm{R} 123$<smiles>FC(F)C(F)(F)F</smiles>

R125<smiles>F/C=C/C(F)F</smiles>

R1234ze

图4＼cjkstart第二、三、四代制冷剂代表化合物

学生感言: 科学的发展是曲折的, 一项科研成果初次提出时, 无法保证完美无缺, 需要不断探 索完善, 减少负面影响, 这正是有机化学研究者的责任与使命。制冷剂从一代到四代的完善历程就 是一个鲜明的例证, 作为化学工作者, 我们应该牢固树立绿色发展的理念, 实现科技成果应用与环 境保护的和谐统一。

\section{3 减轻医疗痛苦, 成果造福人类}

讲授 “卤代烃的用途” 一节中的 “多氟代物” 时, 引入麻醉剂氟烷的临床应用历史, 供学生学 习和讨论。

“扁鹊遂饮二人毒酒, 迷死三日, 剖胸探心, 易而置之; 投以神药, 既悟如初……”用 “毒 酒” “迷死” 病人施以手术，再用 “神药” 催醒是最早的麻醉故事。早期西方用笑气、乙醚、氯仿 等化学麻醉剂进行外科手术。其中, 乙醚是广为知晓的吸入麻醉剂, 但由于其不稳定和易燃易爆等 特性, 被新型麻醉剂取代。

三氟埧氯乙烷(图5), 简称氟烷, 是1956年问世的一个高效低毒的吸入性麻醉剂, 其麻醉作用是 乙醚的四倍, 氯仿的两倍(氯仿常因保存不妥而被氧气氧化, 产生剧毒物质光气, 现在已经停用)。氟 烷不燃烧、不爆炸, 麻醉诱导期很短, 用量少, 对呼吸道无刺激性, 可控性好, 可用于小型手术或 复合麻醉 $[6,7]$ 。<smiles>FC(F)(F)C(Cl)Br</smiles>

图5 氟烷结构式

学生感言: 近代医学发展中, 麻醉剂在不断进步, 安全性不断提高, 化学麻醉剂的发明是人类 的福音。麻醉剂让无数病人免受剧痛, 勇敢地和疾病作斗争, 帮助医生树立医疗信心, 不断攻克医 学难题, 开辟医学新兴研究领域。化学麻醉剂的不断创新推动了医学的进步, 提高了人们的生活幸 
福感, 实现了化学成果用于造福人类。

\section{4 站在天平中央, 倾向人类幸福}

讲授 “卤代烃的合成” 一节中的 “多氯代物” 时, 引入杀虫剂六六六和DDT的兴衰过程, 供学 生学习和讨论。

1825年，英国科学家法拉第(M. Faraday)将苯和氯气在日光下照射, 首次合成了六六六(图6)。 1935年, 科学家发现了六六六的杀虫活性。从此, 六六六作为农药开始在全球大量使用。然而, 六 六六稳定性强, 在环境中不易被降解, 会通过食物链进入人体, 而且难以通过新陈代谢排出体外, 在人体脂肪长期蓄积。当积累到一定程度, 就会使人中毒。1970年开始很多国家禁用六六六, 我国 从1983年开始禁止使用此种农药。<smiles>ClC1C(Cl)C(Cl)C(Cl)C(Cl)C1Cl</smiles>

图6 六六六的合成

二战之后, 世界很多地方传染病横行, 另一种有机氯农药双对氯苯基三氯乙烷(DDT, 图7)的使 用令疮蚊、苍蝇和虫子的肆虐得到有效控制, 并使㾏疾、伤寒和霍乱等疾病的发病率急剧下降。不 过科学家很快就发现, DDT可对神经系统产生毒害, 曾经一度将其禁用 ${ }^{[8]}$ 。但是, 疮疾目前仍是发 展中国家最主要的病因与死因, 由于疮原虫对氯奎宁等治疗药物产生抗药性, 世界卫生组织在2006 年重新提倡使用DDT抗击疮疾。<smiles>Clc1ccc(C(c2ccc(Cl)cc2)C(Cl)(Cl)Cl)cc1</smiles>

图7 DDT结构式

学生感言: 科学技术具有两面性, 在发挥积极作用的同时, 也可能带来一些不利的影响。作为 一名化学工作者, 我们要深入、全面地认识化学物质, 不因其害而弃用, 不因其利而滥用。我们要 用专业知识指导人们科学地利用化学成果, 在规定的尺度内, 合理有效地使用相关化学技术, 实现 其社会价值的最大化。

\section{5 付出总有收获, 创新推动发展}

讲授 “有机金属化合物” 一节中的 “格利雅试剂” 时, 引入科学家格利雅(V. Grignard)的故事和 格利雅试剂的制备及应用, 供学生学习和讨论。

法国化学家格利雅青年时期, 由于家庭生活优越, 是一名 “花花公子”。因在宴会上邀请一位 女伯爵跳舞时被当众拒绝, 格利雅受到很大触动, 从此开始求学之路。后来, 他发明了有机合成中 的重要中间体一一格利雅试剂, 将其应用于有机合成中, 并因此获得1912年诺贝尔化学奖 ${ }^{[9]}$ 。

格利雅试剂是由卤代烃和金属美在无水乙醚或四氢呋喃中反应, 得到的有机金属卤化物(图8)。 格利雅试剂十分活泼, 能与许多含活泼氢的化合物反应生成烃; 与活泼卤代烃反应生成增长碳链的 
烃类化合物; 与酫、酮、环氧化物、羧酸酯等反应生成增长碳链的醇; 与二氧化碳反应生成羧酸, 是有机合成中一种重要的试剂 ${ }^{[10-12]}$ 。

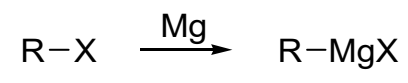

图8 格利雅试剂的制备

学生感言: 我国古代民间有纨绔子弟周处痛改前非除三害的故事, 科学界也有花花公子格利雅 悔过自新发现有机镁试剂的事迹。格利雅的故事告诉我们, 当拥有一颗求知若渴的心, 并付之行动, 总能取得成果。钻研科学的道路没有捷径, 只有不断地探索才能求得真知。

\section{6 结语}

20 世纪以来, 有机化学的分离手段和结构分析方法已经有了很大发展, 许多天然有机化合物的 结构问题纷纷获得圆满解决, 还发现了许多新的重要的有机反应和专一性有机试剂, 每一次有机化 学的新突破都推动了社会的进步, 但同时也会带来潜在的危害。

在这样的新环境下, 教师的责任更加重大, 在教授学生理论知识的过程中, 不仅要传递专业知 识, 还要引导学生探索专业知识背后的深刻内涵。将课程思政与专业课有机统一起来, 帮助学生树 立正确的人生观、价值观、世界观。在潜移默化中, 督促学生养成良好的学习习惯, 营造积极向上 的学习氛围, 激励学生将个人价值与社会价值相结合, 把小我融入大我, 激发其最大潜能, 为中华 民族伟大复兴贡献自己的智慧和力量。

\section{参 考 文 献}

[1] 习近平总书记教育重要论述讲义编写组. 习近平总书记教育重要论述讲义. 北京: 高等教育出版社, 2020.

[2] 徐芷媛, 李莱涵, 张恒, 赵晓霞, 张艳斌, 赵军龙. 大学化学, 2020, 35 (7), 67.

[3] Ronald, J.; Duchovic, R. J. J. Chem. Edu. 2007, 84 (6), 944.

[4] 成广兴, 邵军. 化学通报, 1999, No. 3, 44.

[5] Sicard, A. J. Baker, R. T. Chem. Rev. 2020, 120, 9164.

[6] 佟永生, 王振义. 天津医药杂志, 1963, No. 3, 167.

[7] Brunsvold, R. J. Chem. Edu. 2006, 83 (12), 1821.

[8] 李勇, 孙士铸. 化学教育, 2000, No. 12, 21.

[9] Kagan, H. B. Angew. Chem. Int. Ed. 2012, 51, 7376.

[10] 邢其毅, 裴伟伟, 徐瑞秋, 裴坚. 基础有机化学. 第4版. 北京: 北京大学出版社, 2016.

[11] 赵军龙, 苑沛霖. 基础有机化学反应. 北京: 高等教育出版社, 2018.

[12] 李艳梅, 赵圣印, 王兰英. 有机化学. 第2版. 北京: 科学出版社, 2010. 